\title{
The role of noun imagery in the speed of processing the grammaticality of adjective-noun phrases
}

\author{
DAVID A. GRANT, JEFFREY A. KADLAC, \\ MARIAN SCHWARTZ, and MICHAEL J. ZAJANO \\ University of Wisconsin, Madison, Wisconsin 53706 \\ JOSEPH B. HELLIGE \\ University of Southern California, Los Angeles, California 90007 \\ LOUISE C. PERRY \\ University of Queensland, St. Lucia, Queensland, Australia 4067 \\ and \\ KENNETH B. SOLBERG \\ St. Mary's College, Winona, Minnesota 55987
}

\begin{abstract}
This experiment investigated speed of processing the grammaticality of phrases consisting of the adjective "one" or "two" followed by a singular or plural noun. The subject's task was to press one of two keys, depending upon whether the phrase was grammatically correct or incorrect. There were eight types of phrases, formed by the factorial combinations of singular or plural adjectives, singular or plural nouns, and high or low noun imagery. These served as within-subjects variables. Between-subjects variables were the factorial combinations of sex of subject, duration of stimulus phrase $(.2$ or $2.5 \mathrm{sec})$, and hand assigned to the correct-grammar key. A fourth between-subjects variable was whether or not the subject reported using an artificial phrase-scanning strategy to determine grammaticality. Correct grammar, singular noun form, high noun imagery, and reported use of the strategy all produced highly significant reductions in reaction times. Only $1 \%$ of the interactions were significant. A multistage serial processing model that could be based upon Sternberg's additive factor paradigm or even Donders' subtraction method was found to be highly successful in describing the results.
\end{abstract}

The purpose of the experiment here reported was to investigate the role of rated noun imagery in the processing of adjective-noun phrases by college students. The investigators' interest in this problem developed as a consequence of noun-imagery effects found in a pair of experiments on differential eyelid conditioning

This research was supported in part by grants to the first author from the United States Public Health Service, MH 06792, and from the Research Committee of the Graduate School, using funds provided by the Wisconsin Alumni Research Foundation. Most of the computer analyses were supported in part by the Madison Academic Computing Center of the University of Wisconsin-Madison. The authors all participated in various ways during the several years that went into this research. The authors wish to thank Diane Reamy Halpern, who assisted them in running subjects and in analyzing data, and William A. Benish and William $\mathrm{J}$. Cody, who contributed to interpretation of the data and and improved the theoretical model proposed. Reprint requests should be directed to David A. Grant, W. J. Brogden Psychology Building, 1202 West Johnson, University of Wisconsin-Madison, Madison, Wisconsin 53706; or Louise C. Perry, Department of Psychology, University of Queensland, St. Lucia, Queensland, Australia 4067. which used the grammaticality of adjective-noun phrases as the discriminative stimulus (Perry, Grant, \& Schwartz, in press). The basic finding was that grammaticality was a more effective discriminative stimulus when the phrases contained high-imagery nouns than when they contained low-imagery nouns. Interpretation of such a result requires more understanding of how noun imagery affects the ways subjects test the grammaticality of simple adjective-noun phrases. It was hoped that the present experiment would shed some light on the possibility that differences in processing times between phrases containing high- vs. low-imagery nouns might have accounted for the conditioning results found by Perry et al.

In addition, it was hoped that the present experiment would help elucidate the imagery effects found in a variety of other paradigms. In particular, it appears that high imagery or concreteness facilitates sentence comprehension and verification (cf. Holmes \& Langford, 1976; Jorgenson \& Kintsch, 1973; Klee \& Eysenck, 1973; Paivio \& Begg, 1971; Paivio \& Ernest, 1971), but it is not known whether the generation of mental 
images, per se, plays a role in producing these effects. Some investigators (Jorgenson \& Kintsch, 1973; Klee \& Eysenck, 1973; Paivio, 1971, p. 179ff) have implicated actual mental imaging, but doubts on this point have recently been expressed by a number of investigators (e.g., Anderson \& Bower, 1972; Kintsch, 1974; Postman, 1975; Pylyshyn, 1973; Wickens \& Engel, 1970). Clearly, more work will be required to define the locus and the nature of the imagery effect in processing semantics and syntax.

The design of the present experiment was based on Sternberg's additive factor extension of Donders' subtraction method (Sternberg, 1969), with numerous converging operations (Garner, Hake, \& Eriksen, 1956; Pachella, 1974) permitted by insertion of a number of independent variables to search for interaction effects. It was reasonable to believe that this approach would be analytic, because Carpenter and Just (1975) and Trabasso (1972) were successful in employing the Sternberg paradigm to develop limited models for language comprehension.

\section{METHOD}

In outline, the experiment consisted of four parts: practice, reaction time (RT) task, recognition task, and questionnaire. In the RT task, the subject pressed one of two keys to indicate whether a visually presented adjective-noun was grammatically correct or incorrect. It was anticipated that some subjects might try to use an artificial phrase-scanning strategy in determining the grammaticality of the phrases; that is, a strategy of reading the adjective and then looking immediately to see if the noun ended with an "s." As it was desired to encourage subjects to attend to the entire phrase instead of using this strategy, the RT instructions informed them that they should remember the nouns for a subsequent recognition test, and the recognition test was in fact administered.

\section{Stimulus Materials}

The adjective-noun phrases were the same as those used in Experiment 2 of the study by Perry et al. (in press). Each phrase contained the adjective "one" or "two" paired with the singular or plural form of the noun. "Good" grammar was represented by a singular adjective paired with a singular noun or a plural adjective paired with a plural noun. "Bad" grammar was represented by a singular adjective paired with a plural noun or a plural adjective paired with a singular noun. The nouns had been selected from the Paivio, Yuille, and Madigan (1968) norms. They were restricted to those whose plural forms ended with an
" $s$ " and whose singular forms did not. The nouns were divided into two sets, each containing 40 high-and 40 low-imagery nouns. (Throughout this paper, the nouns will be referred to as differing in imagery ratings, although they also differed in concreteness, which correlates highly with imagery.) Each 80-noun set was used in the RT phase of the experiment for half the subjects and was used as foils in the subsequent noun recognition test for the remaining subjects. The two sets were matched as closely as possible for number of letters, number of syllables, average imagery rating, average familiarity $(\mathrm{m})$ by Noble's (1952) production method, and Thorndike-Lorge (1944) frequency. The mean values for these characteristics by set and imagery level are given in Table 1 . Subsequent to the experiment, examination of the Kucera-Francis (1967) frequency counts of our high- and low-imagery nouns revealed that the low-imagery nouns had somewhat higher frequency than did the high-imagery nouns (average word counts of 71.21 and 65.53, respectively).

Eight sets of 80 phrases were constructed for each set of 80 nouns. In all sets, the sequence of phrases was randomized within eight-trial blocks, each of which contained four high- and four low-imagery nouns with all four adjective-noun contingencies represented at both levels of imagery. The phrases were arranged in four sequence orders so that each noun could appear in all four types of phrases: singular adjective singular noun (SS), plural adjective plural noun (PP), plural adjective singular noun (PS), and singular adjective plural noun (SP).

The grammaticality of the phrases and the imagery of the nouns were counterbalanced across the eight sets, and the nouns were spaced to as to avoid any confound between serial position and any of the variables of interest.

\section{Apparatus}

The subject sat in a double sound-proofed chamber approximately $170 \mathrm{~cm}$ from a ground glass screen which was located at the rear of a white rectangular enclosure $85 \mathrm{~cm}$ wide, $65 \mathrm{~cm}$ tall, and $88 \mathrm{~cm}$ deep. Instructions to the subjects inside the chamber and other communications were by intercom.

The phrases were photographed on high-contrast film and overexposed so that on the negatives the phrases appeared white on a very dark background. The stimuli were back-projected onto the center of the screen by means of a Kodak Ektographic slide projector. The projected size of the stimuli was $1.11 \mathrm{~cm}$ in height (visual angle, $.59 \mathrm{deg}$ ) for the initial capital letters and $.8 \mathrm{~cm}$ or $.43 \mathrm{deg}$ for small letters. The length of the phrase varied from $6.35 \mathrm{~cm}(3.4 \mathrm{deg})$ to $14 \mathrm{~cm}(7.45 \mathrm{deg})$.

On a board in front of the subjects were mounted three telegraph keys. The middle key was not used. The two outside keys were $16 \mathrm{~cm}$ apart and were labeled with letters " $G$ " and "B" for good and bad grammar, respectively. For half of the subjects the $G$ key was on the right and for the remaining subjects the $B$ key was on the right. Reaction times were recorded on a digital clock outside the chamber, and monitoring lights indicated to the experimenter whether the subject had given the correct response to the phrase. The subject, however, received no information as to his errors.

Table 1

Characteristics of the Sets of Nouns Used in the Two Experiments (Mean Values)

\begin{tabular}{|c|c|c|c|c|c|c|c|}
\hline \multirow[b]{2}{*}{$\begin{array}{l}\text { High Imagery } \\
\text { Set } 1 \\
\text { Set } 2\end{array}$} & \multirow{2}{*}{$\begin{array}{c}\begin{array}{c}\text { Number of } \\
\text { Letters }\end{array} \\
7.31 \\
7.22 \\
7.40\end{array}$} & \multirow{2}{*}{$\begin{array}{c}\begin{array}{c}\text { Number of } \\
\text { Syllables }\end{array} \\
2.52 \\
2.48 \\
2.58\end{array}$} & \multirow{2}{*}{$\begin{array}{c}\begin{array}{c}\text { Imagery } \\
\text { Rating }\end{array} \\
6.32 \\
6.37 \\
6.27\end{array}$} & \multirow{2}{*}{$\begin{array}{c}\begin{array}{c}\text { Concrete- } \\
\text { ness } \\
\text { Rating }\end{array} \\
6.58 \\
6.57 \\
6.59\end{array}$} & \multirow{2}{*}{$\begin{array}{c}\begin{array}{c}\text { Familiarity (m) } \\
\text { by Noble's Pro- } \\
\text { duction Method }\end{array} \\
6.49 \\
6.57 \\
6.41\end{array}$} & \multicolumn{2}{|c|}{$\begin{array}{l}\text { Thorndike-Lorge } \\
\text { Frequency }\end{array}$} \\
\hline & & & & & & $\begin{array}{l}14.37 \\
13.96 \\
14.80\end{array}$ & $\begin{array}{l}(+14 \mathrm{~A}, 15 \mathrm{AA}) \\
(+7 \mathrm{~A}, 7 \mathrm{AA}) \\
(+7 \mathrm{~A},\end{array}$ \\
\hline $\begin{array}{l}\text { Low Imagery } \\
\text { Set } 1 \\
\text { Set } 2\end{array}$ & $\begin{array}{l}7.31 \\
7.22 \\
7.40\end{array}$ & $\begin{array}{l}2.56 \\
2.58 \\
2.55\end{array}$ & $\begin{array}{l}3.27 \\
3.26 \\
3.27\end{array}$ & $\begin{array}{l}3.18 \\
3.32 \\
3.04\end{array}$ & $\begin{array}{l}5.21 \\
5.31 \\
5.11\end{array}$ & $\begin{array}{l}14.29 \\
13.92 \\
14.68\end{array}$ & $\begin{array}{l}(+16 \mathrm{~A}, 13 \mathrm{AA}) \\
(+8 \mathrm{~A}, 6 \mathrm{AA}) \\
(+8 \mathrm{~A}, 7 \mathrm{AA})\end{array}$ \\
\hline
\end{tabular}


Subjects and Experimental Design

Thirty-two men and 32 women undergraduate students at the University of Wisconsin participated in the experiment to fulfill part of a requirement for introductory psychology courses. All subjects were right-handed and had English as their native language. The data of three additional subjects were rejected, one because of his unusually high error rate, $25 \%$, another because she had been in a similar experiment, and the third because he pressed the left key with his right hand and vice versa.

Eight subjects were assigned to each of the eight experimental treatment conditions that resulted from the factorial arrangement of three between-subjects variables: the duration of the stimulus ( $2.5 \mathrm{sec}$ or $.2 \mathrm{sec})$, sex of subjects, and hand used to press the G (good grammar) key. (The variable of stimulus duration was employed to see whether stimulus duration would interact with noun imagery. It did not.) In spite of the warning given the subjects that there would be a noun recognition test after the RT phase of the experiment, some of the subjects indicated during the postexperimental inquiry that, in determining the grammaticality of the phrases, they had used the artificial strategy mentioned earlier. Reported use of the strategy was, therefore, treated as a fourth between-subjects variable. In addition to the four between-subjects variables, there were three within-subjects variables: singular or plural form of the adjective, singular or plural form of the noun, and high or low imagery of the nouns.

\section{Procedure}

Before entering the sound chamber, each subject was tested for normal vision. After the subject was seated in the chamber, he was shown a chart containing an example of each of the four types of phrases: singular adjective singular noun (SS), plural adjective plural noun (PP), plural adjective singular noun (PS), and singular adjective plural noun (SP). The four phrases on the chart were characterized as "good" or "bad" grammar, and it was pointed out that the keys labeled " $G$ " and " $B$ " represented good and bad grammar, respectively. The four nouns were of intermediate imagery rating. The subject was then informed that prior to each trial there would be a brief ready signal and "shortly afterward the noun phrase will appear on the screen. Your task will be to press one of the two keys. . quickly and accurately . . to indicate whether the phrase was good grammar or bad grammar." In addition, the subject was told that, after pressing the key, he was to pronounce the noun aloud once, so that it could be remembered more easily for the recognition test which would follow the reaction time task.

After removal of the chart, the subject was given four demonstration trials, in which the chart phrases appeared on the screen, in order to determine whether he understood the procedure. The instructions were then repeated, emphasizing the two tasks, RT and noun recognition, and the subject was informed that he would be given some practice trials. The practice trials consisted of five phrases of each of the four types. The nouns were of intermediate imagery (mean imagery rating 4.75 ). Following these practice trials, the 20 practice nouns were paired with 20 other nouns of intermediate imagery in a practice recognition test similar to the one given later for the experimental nouns. The subject was then informed that the experiment proper would begin and was again reminded of the two tasks: RT and noun recognition. The 80 experimental trials were then given.

On all RT trials, the time between the onset of one stimulus phrase and the onset of the next was $12 \mathrm{sec}$. Stimulus duration was either $2.5 \mathrm{sec}$ or $.2 \mathrm{sec}$. On each trial, the onset of the ready signal (a tone of $500 \mathrm{~Hz}, 66-68 \mathrm{~dB}, 500 \mathrm{msec}$ in duration) was always 1 sec prior to stimulus onset.

Following presentation of the 80 adjective-noun phrases, the subject was given a written, untimed recognition test consisting of 80 pairs of nouns. Each pair contained one of the nouns used in the experimental trials of the RT task paired with a foil from the other 80-noun set. Both nouns were in their singular form. In half the pairs the foil had the same imagery rating (high or low) as the target noun; in half the foil had the other imagery rating. The subject was told that one noun of each pair had appeared during his RT task and that he was to circle the noun that he recognized as having appeared earlier. Four different sequences of recognition items were constructed such that every target noun appeared with a different foil in each sequence. One-fourth of the subjects in each of the eight experimental treatment conditions received each sequence. Finally, after completing the recognition test, the subject was asked to fill out a written questionnaire about the experiment. Among other things, the questionnaire was aimed at obtaining information as to whether the subject was aware of the possibility of using the phrase-scanning strategy (reading the adjective and then looking immediately to see if the noun ended with an " $s$ ") and whether he thought that he had used it. The subject was then interviewed further to verify that he was or was not aware of the strategy, and if so, the percentage of the time that he thought that he had used it.

\section{RESULTS}

\section{Statistical Analysis of the Reaction Time Data}

The 64 subjects gave a total of 5,120 RTs and made errors (i.e., called correct grammar incorrect or vice versa) on 264 of the phrases, an overall error rate of $5 \%{ }^{1}$ The statistical analyses were performed on the RTs of correct responses only. Each subject received eight kinds of stimulus phrases, the factorial combinations of high or low noun imagery, singular or plural adjectives, and singular or plural nouns. For each subject, the median RT on each of the eight kinds of phrases was obtained, and all further statistical analyses were done on the means of these medians so that a Sternberg analysis would be valid.

In this type of experiment, the use of individual subjects' median RTs has four advantages over the use of subjects' means. (1) Medians are less influenced by the skewed RT distributions of individual subjects. (2) Extremely short and extremely long RTs do not influence the median. (3) If certain of the subjects have idiosyncratic reactions to certain of the nouns, the use of medians tends to prevent these idiosyncracies from influencing the analyses. (4) Finally, if the subject changes his mode of processing early in the experiment, the use of the median is likely to be the RT of his dominant processing mode.

On the basis of their responses to the questionnaire and subsequent further interview by the experimenter, 25 of the 64 subjects were judged to have used the phrase-scanning strategy on $50 \%$ or more of the RT trials. These 25 subjects will be labeled "strategy users"; the remaining subjects "strategy nonusers." Because these 25 subjects were unequally distributed in the eight experimental groups, it was necessary to use an analysis of variance that took into account the unequal subcell frequencies. Six different unweighted means analyses were performed on the same data, grouping different sets of cells in different ways in the analyses. Grouping the cells differently was desirable in order to base each unweighted cell mean on the largest number of median 
Table 2

Sources of Variation Producing Fs With $p<.05$

\begin{tabular}{lc}
\hline Source of Variation & Median F \\
\hline Grammar (Gr) & $71.80^{* * *}$ \\
Noun Form (NF) & $31.11^{* * *}$ \\
Imagery (I) & $17.21^{* * *}$ \\
Strategy (St) & $6.94^{* \dagger}$ \\
Gr by Key & $4.78^{*}$ \\
Gr by NF & $4.68^{*} \dagger$ \\
St by I by NF & $6.80^{*}$ \\
St by NF by Dur by Key & $6.06^{*} \dagger$ \\
Dur by Key by Sex by I by Gr & $4.64^{*}$ \\
Dur by Key by St by Gr by NF & $4.22^{*}$ \\
\hline
\end{tabular}

Note-The figures shown are the median Fs from the six unweighted means analyses performed on the median reaction times. Degrees of freedom varied from $1 / 56$ to $1 / 60$ in the six analyses.

${ }^{*} p<.05$

$t$ At least one $F$ significant at .01 level.

${ }^{* *} p<.01$

$* * * p<.001$

RTs for testing of any given interaction. In these different analyses, a total of $32 \mathrm{Fs}$ were computed for main effects and $258 \mathrm{Fs}$ were computed for interactions. Because of the large number of $F$ tests, it was decided that in order to reduce the risk of Type I errors a double criterion should be used to decide statistical significance. An $F$ was judged statistically significant by a stronger criterion if its median value in the six unweighted means

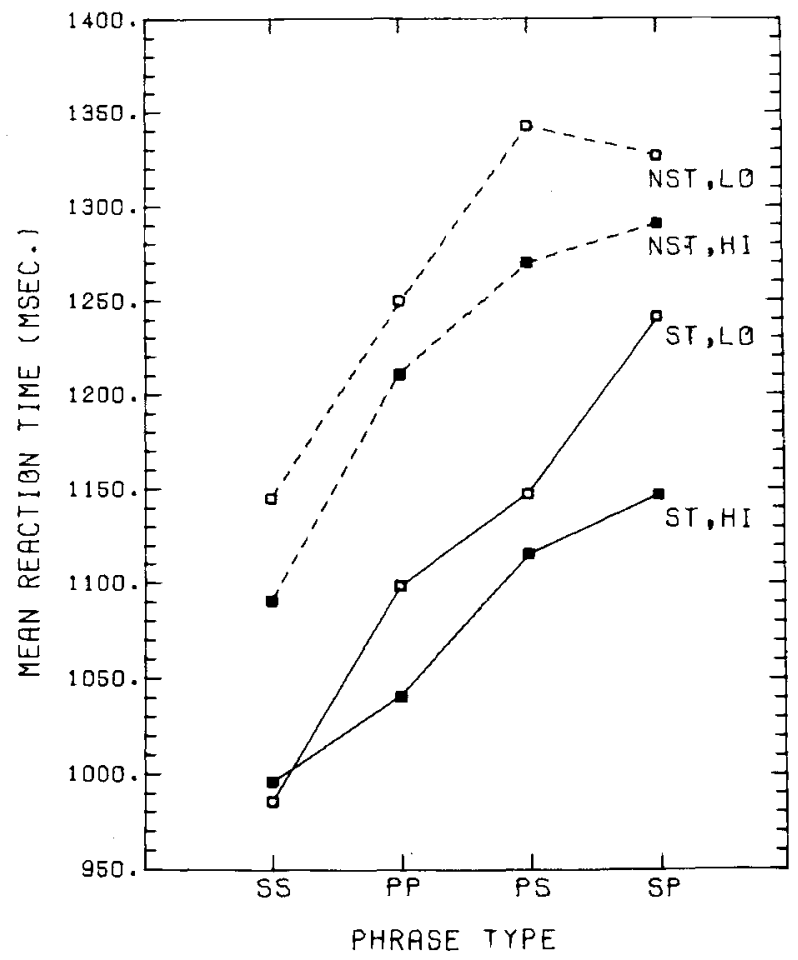

Figure 1. Mean of subjects' median RTs in milliseconds, plotted for the singular adjective singular noun (SS), plural adjective plural noun (PP), plural adjective singular noun (PS), and singular adjective plural noun (SP) phrases. The parameters are: (1) reported use of the strategy, users (ST, solid lines), nonusers (NST, dashed lines), (2) noun imagery, high (HI, closed symbols), or low (LO, open symbols). analyses was significant at the .01 level; or by a weaker criterion if the effect in question produced one or more Fs significant at the .01 level in any of the unweighted means analyses.

The median Fs for all effects with $p<.05$ are shown in Table 2, although only those meeting Criterion 1 or Criterion 2 above were judged significant. Those Fs that met Criterion 2 only are marked with a dagger $(t)$ in the text and in Table 2.

\section{Reaction Time Results}

All data points in Figures 14 were from the weighted means analyses, and because the subjects' responses were grouped differently in the different analyses, slight apparent inconsistencies will appear between the different figures. In Figure 1 are plotted the means of the median RTs in milliseconds as a function of the four phrase types. Data are plotted separately for high and low noun imagery and for those subjects who did and did not report using the strategy. The mean RTs ranged from about 900 to about $1,400 \mathrm{msec}$. Noun imagery, grammaticality (i.e., correct or incorrect grammar), noun form (singular or plural), and use of the strategy produced 22 significant $\mathrm{Fs}$, or $69 \%$ of the 32 computed. There were no significant main effects of the other variables: adjective form (singular or plural), stimulus duration, or hand used to indicate correct grammar. Only two, or $1 \%$, of the 258 interaction $F$ s were significant.

Grammatically correct phrases (SS and PP) produced reaction times about $127 \mathrm{msec}$ faster than did the grammatically incorrect phrases (PS and SP), and subjects who reported using the strategy gave reaction times about $135 \mathrm{msec}$ faster than those who did not report using the strategy. The effects of grammaticality, noun imagery, and use of the strategy were highly significant main effects [median Fs $(1,62)=71.80,17.21$, and $6.94 \dagger$, respectively]. The only significant interaction among the three factors in Figure 1 was between grammaticality and noun form [median $F(1,56)=6.80 \dagger]$. This interaction is pictured in Figure 2, which shows that noun form had a greater effect for grammatical phrases than for ungrammatical phrases. For example, in one analysis where the interaction $F=8.05$, the unweighted means for grammatically correct phrases were 1,067 and $1,167 \mathrm{msec}$ for singular and plural nouns, respectively, whereas the corresponding means for grammatically incorrect phrases were 1,238 and $1,264 \mathrm{msec}$, respectively.

In Figure 3 the four phrase types are classified as simply correct, G+ (SS and PP), or incorrect, G- (SP and PS). The parallel lines of Figure 3 show that the effects of grammaticality, strategy, and imagery are simply additive. None of the interactions of these three variables were statistically significant, all Fs being less than 1.0. Unexpectedly, the effect of noun imagery on RT was the same regardless of whether the subject reported using the phrase-scanning strategy.

In Figure 4 the RTs are plotted as a function of noun imagery, reported use of the strategy, and form of the 


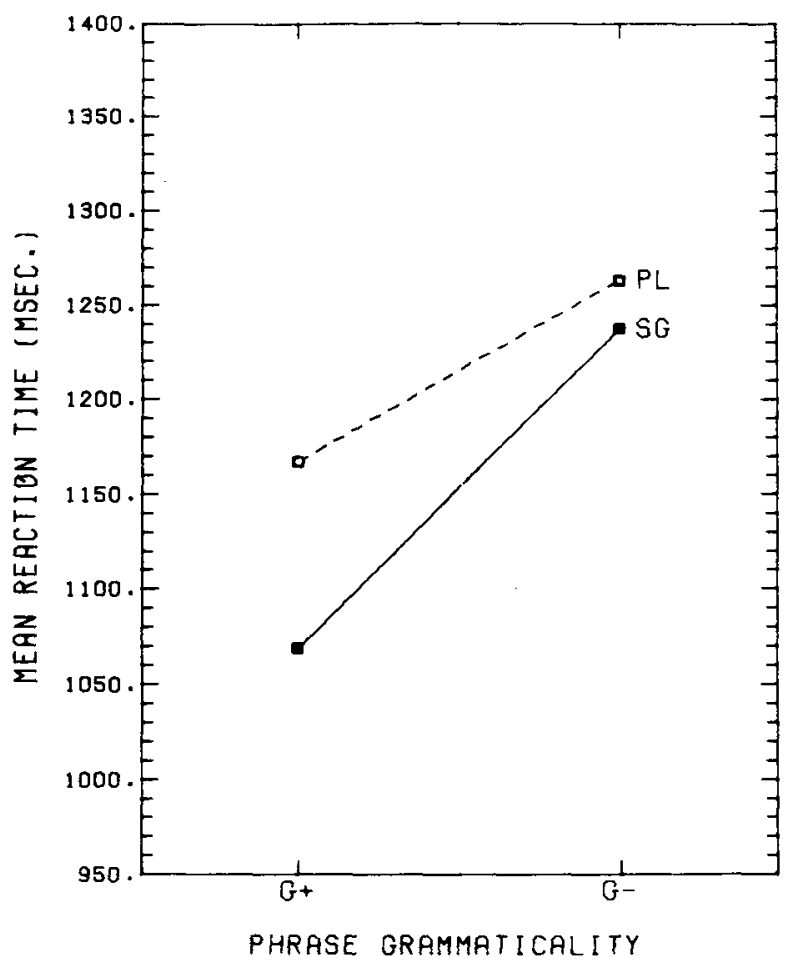

Figure 2. Means of median RTs plotted for grammatically correct $\left(G^{+}\right)$and incorrect $(G-)$ phrases. The parameter is form of the noun, singular (SG) or plural (PL).

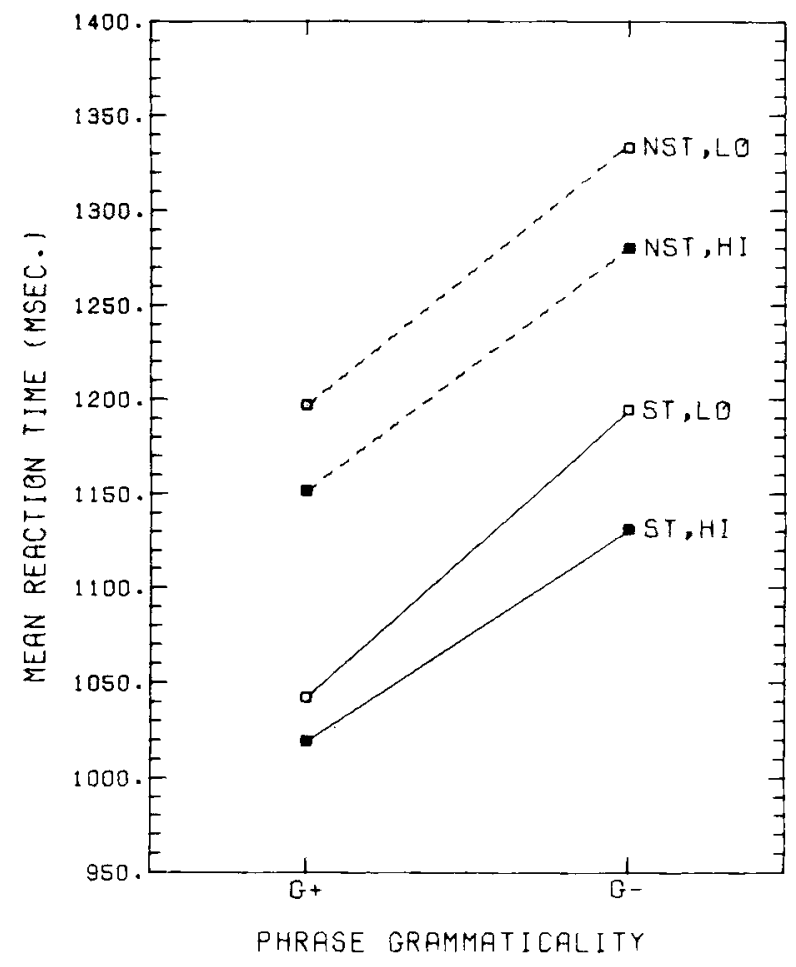

Figure 3. Means of the median RTs plotted for grammatically correct (G+) and incorrect (G-) phrases. The parameters are: (1) reported use of the strategy, users (solid lines), nonusers (dashed lines), and (2) noun imagery, high (HI) or low (LO).

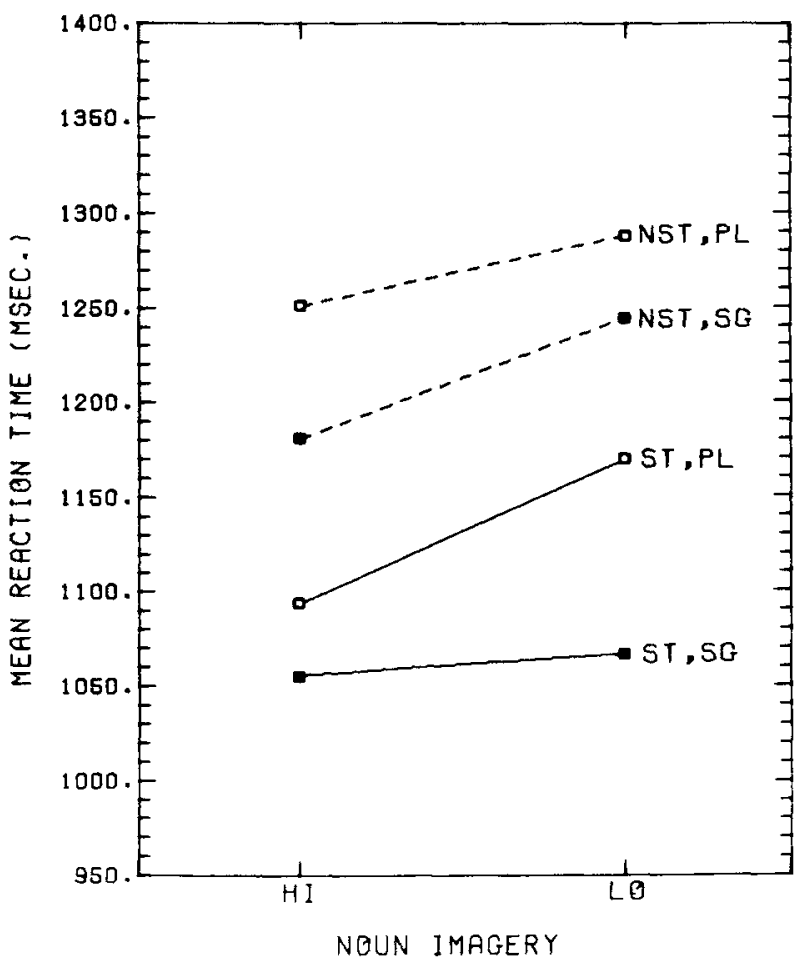

Figure 4. Means of median RTs plotted for phrases containing nouns with high (HI) and low (LO) imagery ratings. The parameters are: (1) strategy, users (ST, solid lines), nonusers (NST, dashed lines), and (2) form of the nouns, singular (SG), or plural (PL).

nouns. The singular noun form produced a statistically significant decrease in reaction time $[\mathrm{F}(1,60)=31.11]$. The singular or plural form of the adjectives produced no significant effect $[F(1,60)=3.10]$. Again, none of the two-factor interactions were statistically significant, but the three-factor interaction, Strategy by Noun Imagery by Noun Form, was $[F(1,56)=6.80 \dagger]$. As shown in Figure 4 , the interaction arises because noun imagery did not affect the RTs of strategy users to phrases containing singular nouns but did affect their RTs to phrases containing plural nouns, whereas for nonusers of the strategy the factors of noun imagery and noun form were very nearly additive.

\section{Recognition Memory for Nouns}

In the recognition test, the variable of foil imagery was added to the seven variables in the RT experiment, and this produced a total of 256 treatment conditions. Two analyses were performed on the data.

In both analyses only one main effect was statistically significant. There were fewer errors if the foil was a high. imagery noun (9.07) than if it was a low-imagery noun (13.18) [median $F(1,56)=19.04, p<.001]$. None of the 240 interaction Fs were significant. Recognition errors averaged $13.9 \%$.

The finding that no RT task variable had any significant effect on the recognition test results can most 
reasonably be attributed to extensive rehearsal of the nouns during the intertrial intervals of the RT task. Since the subjects expected the recognition test, it is likely that they took advantage of the $12-\mathrm{sec}$ intertrial intervals to rehearse the nouns, and that rehearsal may well have eliminated any effects of the RT variables upon later recognition performance.

\section{DISCUSSION}

\section{A Serial Model For Processing The Grammaticality of Adjective-Noun Phrases}

The RT data fell into a striking pattern: There were many significant main effects, but only two, or $1 \%$, of the interaction Fs met the criterion of significance. This pattern implies that Sternberg's (1969) additive factor method or possibly even Donders' subtraction model can provide a useful description of the results. A heuristic multistage serial processing model is presented in Figure 5.

The experimental data and logical considerations seem to demand the seven encoding and processing stages shown in Figure 5 . The sequence of stages shown appears to be the most logical one: (1) initial adjective encoding, (2) initial noun encoding, (3) processing the noun for imagery level, (4) encoding for phrase processing, (5) processing for noun form, (6) processing for grammaticality, and (7) response translation and execu. tion.

Before discussing Figure 5, it is necessary to review the RT data relative to use of the phrase-scanning strategy. The following points should be noted: (1) On the basis of the postexperimental questionnaire and interview, subjects were classified as being either users or nonusers of the artificial phrase-scanning strategy during the RT task (i.e., reading the adjective and then looking immediately to see if the noun ended in $\mathrm{s}$ ). The classification was based on an admittedly rough measure-the subject's estimate of the percentage of trials on which he thought he had used this strategy. If the percentage was $50 \%$ or more, the subject was labeled a strategy user. (2) Those who were labeled strategy users averaged $135 \mathrm{msec}$ faster in their RT responses than those labeled nonusers. Therefore, this classification reflects a difference of some kind in the way these two sets of subjects were processing the phrases during the RT task. (3) The noun imagery effect was of equal magnitude in both sets of subjects; the additional processing times required for low-imagery as compared with high-imagery noun phrases amounted to $50 \mathrm{msec}$ for the strategy users and $48 \mathrm{msec}$ for the nonusers. Therefore, whatever the strategy users thought they were doing, they were processing the nouns for imagery value and they were probably doing this in the same way as were the nonusers. (4) The additional processing time required for plural nouns as compared with singular nouns did not differ significantly for strategy users $(80 \mathrm{msec})$ and for nonusers (54 msec). (5) Also, the additional processing time required for bad grammar as compared with good grammar did not differ significantly for users $(118.92 \mathrm{msec})$ and for nonusers $(140.50 \mathrm{msec})$. Therefore strategy users probably did not differ from nonusers in the way they were processing the phrases for noun form and for grammaticality. It appears that those subjects who reported using the phrase-scanning strategy on at least half the trials succeeded in shortening their overall RT by an average of $135 \mathrm{msec}$, but did this without shortening the processing time for noun imagery, noun form, or grammaticality.

Turning now to Figure 5, the first stage (assuming normal reading habits) would be recognition and encoding of the adjective. This would probably occur quite rapidly because of the high familiarity of the words "one" and "two." Noun recognition and encoding should follow immediately. Processing of the noun for imagery must be represented as a separate serial stage, as the imagery effect is additive with respect to all the other variables in the experiment, including use or nonuse of the phrase-scanning strategy. The most logical locus of this stage is immediately following noun encoding.

The phrase-scanning strategy is represented next. As the strategy users shortened their overall RT by a mean of $135 \mathrm{msec}$ without shortening the processing time for noun imagery, noun form, or grammaticality, the assumption was made that nonusers went through a stage labeled, somewhat arbitrarily, "encoding for phrase processing," and that users bypassed or shortened this stage.

In the next stage, processing for noun form, the noun is identified as being either singular or plural, with plural nouns requiring a mean of $67 \mathrm{msec}$ more than singular nouns. Only a fraction of this additional time can be attributed to the greater length of the plurals, as addition of another letter ordinarily increases word recognition time by only 10 to $15 \mathrm{msec}$ (Theios \& Muise, Note 1). It is possible that the faster processing of the singular nouns is due mainly to a familiarity effect. Reference to the Kucera-Francis (1967) norms reveals that the singular nouns that were used in this experiment occur more frequently in English than do the corresponding plurals; the mean frequency was 43.08 for the singular forms and $\mathbf{1 7 . 5 3}$ for the plurals, based on a corpus totaling $1,014,232$ words.

The next stage shown in Figure 5 is the test for grammaticality. If the phrase was grammatically incorrect, there was a further processing delay that averaged $127 \mathrm{msec}$. Perhaps the simplest interpretation of this delay would be that grammatically correct phrases are more familiar than grammatically incorrect ones, and it is well known that stimulus familiarity has an important facilitating effect on RT (Krueger, 1975; Rubenstein, Lewis, \& Rubenstein, 1971).

Following completion of the grammaticality test, 


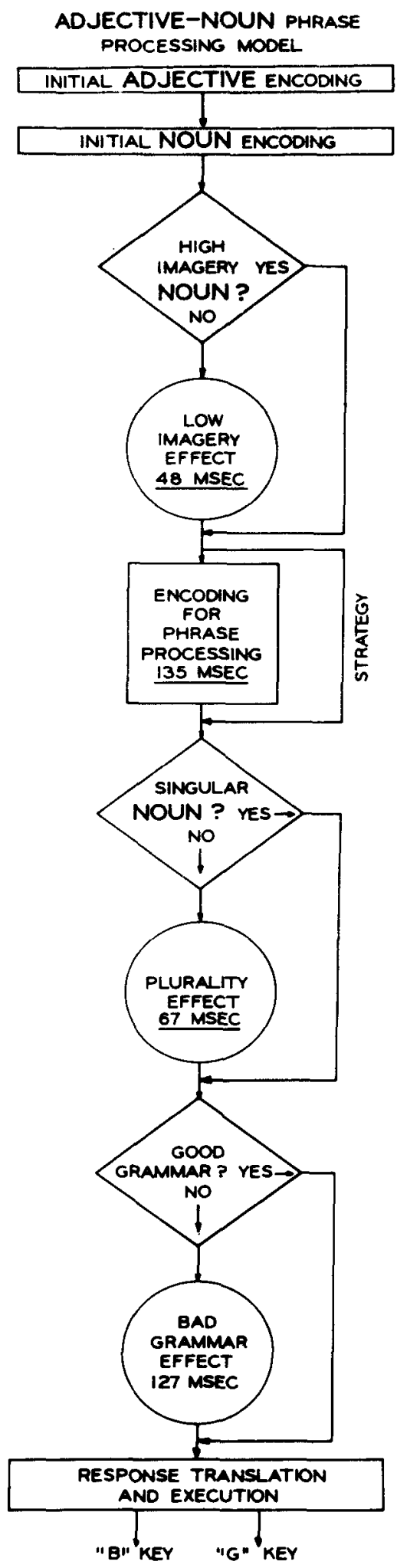

Figure 5. A heuristic serial model for processing the grammaticality of the adjective-noun phrases. The model is described in text. response translation and execution can occur, ending the processing of the phase.

The strong additivity of the main effects suggests that our model is an excellent initial approximation to simulating the psychological operations necessary to process these phases.

\section{Nature of the Imagery Effect}

The present results appear to rule out one possible explanation for the Perry et al. (in press) finding that grammaticality was a more effective discriminative stimulus (in eyelid conditioning) when the adjectivenoun phrases contained high-imagery nouns. Had there been a fairly large difference in processing time between high- and low-imagery noun phrases in the present experiment, it could be argued that the length of the effective CS-UCS interval in the Perry et al. study was closer to optimum for the high-than for the low-imagery noun phrases. The present experiment, however, shows only a $48-\mathrm{msec}$ difference in RT as a function of noun imagery, and our unpublished data indicate that for verbal differential stimuli the optimal CS-UCS interval would be about $1,000 \mathrm{msec}$. Accordingly, the possibility seems remote that a difference in processing time as small as $48 \mathrm{msec}$ within a $1,000-\mathrm{msec}$ CS-UCS interval could give a complete account of the Perry et al. results. While the role of imagery in the Perry et al. study remains unclear, it may well have been mediated by the factor of subject awareness; questioning indicated that awareness of the discriminative cue, grammaticality, was significantly more frequent among subjects who had been shown the high-imagery nouns.

The present findings may have a broader implication for imagery effects on verbal behavior. It seems quite possible that in paired associate learning (Paivio, 1971, pp. 247-272), sentence comprehension or verification (e.g., Ellis \& Shepherd, 1974; Holmes \& Langford, 1976; Klee \& Eysenck, 1973; Paivio \& Begg, 1971; Paivio \& Ernest, 1971), and so on, the locus of the noun imagery effect may lie in the stage of recognizing and encoding the nouns. Investigation of this possibility could prove helpful in developing a better theoretical understanding of imagery effects in general. If the locus of the effect is in the recognition and encoding stage, imagery should produce an effect on speed of sentence verification, and so on, which would be simply additive to effects of other variables that affect later stages of verbal processing. If certain variables produce interactions with imagery, presumably these variables affect processing at the same locus as that of the imagery effect. Thus the Sternberg additive-factor method could reveal the number and nature of the stages required to process more complicated syntax and semantics. The large number of stages that apparently are involved in processing the grammaticality of simple adjective-noun phrases suggests, however, that investigation of the processing of more complex syntax will be no easy 
matter. But the success of this experiment and those of Carpenter and Just (1975) and Trabasso (1972) in applying the Sternberg approach to sentence comprehension offer some encouragement to investigators who wish to clarify this complex area of research.

\section{REFERENCE NOTE}

1. Theios. J., \& Muise. J. G. The word identification process in reading. Report Number 75-1. Wisconsin Human Information Processing Program. December 1975.

\section{REFERENCES}

Anderson, J. R., \& Bower. G. H. Recognition and retrieval processes in free recall. Psychological Review, 1972. 79. 97-123.

Carpenter. P. A.. \& Just. M. A. Sentence comprehension: A psycholinguistic processing model of verification. Psychological Revieu, 1975. 82, 45.73.

Ellis. H. D., \& Shepherd. J. W. Recognition of abstract and concrete xords presented in the left and right visual fields. Journal of Experimental Psychology. 1974, 103. 1035-1036.

Garner. W. R.. Hake. H. W., \& ERIKsen. C. W. Operationism and the concept of perception. Psychological Review, 1956. 63. 149-159.

Holmes. V. M.. \& LANGFoRD. J. Comprehension and recall of abstract and concrete sentences. Joumal of Verbal Learming and Verbal Behavior. 1976. 15. 559-566.

JoRGENSEN. C. C.. \& Kintsch. W. The role of imagery in the evaluation of sentences. Cognitive Psychology. 1973. 4. 110-116.

KINTSCB. W. The representation of meaning in memory. Hillsdale. N. J: Lawrence Erlbaum. 1974.

KLEE. H.. \& Eysencr. M. W. Comprehension of abstract and concrete sentences. Journal of Verbal Learning and Verbal Behavior. 1973, 12, 522-529.

KRUEGER, L. E. Familiarity effects in visual information process ing. Psychological Bulletin, 1975, 82, 949-974.

Kućera, H.. \& Francis. W. N. Computational anabysis of present-day American English. Providence. R. I: Brown University Press. 1967.

Noble. C. E. An analysis of meaning. Psychological Review. 1952. 59. $421-450$.

PACHella, R. G. The interpretation of reaction time in informationprocessing research. In B. H. Kantowitz (Ed.), Human information processing: Tutorials in performance and cognition. New York: Wiley. 1974. Pp. 1-40.
Parvio, A. Imagery and verbal processes. New York: Holt, 1971.

Parvio, A., \& Begg, I. Imagery and comprehension latencies as a function of sentence concreteness and structures. Perception \& Psychophysics, 1971, 10, 408-412.

Parvo, A., \& ERnest, C. H. Imagery ability and visual perception of verbal and nonverbal stimuli. Perception \& Psychophysics. $1971,10,429-432$.

Paivio, A., Yuille, J. C.. \& Manigan, S. A. Concteteness. imagery, and meaningfulness values for 925 nouns. Journal of Experimental Psychology Monograph Supplement, 1968, 76. Part 2, 1-25.

Perry. L. C.. Grant, D. A., \& Schwartz, M. Grammaticality of high- and low-imagery noun phrases as a discriminandum in differential eyelid conditioning. Memory \& Cognition, in press.

Postman. L. Verbal learning and memory. Annual Revien of Psychologv, 1975, 26. 291-335.

Pyr.ysern, Z. W. What the mind's eye tells the mind's brain: A critique of mental imagery. Psychological Bulletin, 1973, 80. 1-24.

Rubenstein. H., Lewis, S. S.. \& Rubenstein, M. A. Evidence for phonemic recoding in visual word recognition. Journal of Verbal Learning and Verbal Behavior. 1971, 10. 645-647.

STERNBERG. S. The discovery of processing stages: Extensions of Donders' method. Acta Psychologica, 1969, 30. 1975.

THORNDIKE. E. L. \& LORGE. 1. The teachers word book of 30.000 words. New York: Bureau of Publication. Teachers College. Columbia University. 1944.

Trarasso. T. Mental operations in language comprehension. In J. B. Carroll \& R. O. Freedle (Eds.). Language comprehension and acquisition of knowledge. Washington. D.C: V. A. Winston. 1972. Pp. 113-137.

WiCKens. D. D.. \& ENGEI. R. W. Imagery and abstractness in short-term memory. Joumal of Experimental Psychology. 1970. 84. $268-272$.

\section{NOTE}

1. There was no evidence that a speed-accuracy tradeoff played a part in any of the significant RT results. If anything, conditions under which faster RTs were obtained tended to produce somewhat fewer errors. A possible exception may be noted for the duration variable (which had no significant RT effects): Short exposures produced more errors (7.3\%) than did long exposures $(2.7 \%)$.

(Received for publication January 13, 19:7; revision accepted A pril 26, 1977.) 